\title{
An Exploration on Sustainable Development of Sports Service for Community from the Perspective of Public Service
}

\author{
Shaohui Yuan ${ }^{1, a}$ \\ ${ }^{1}$ Hebei Vocational and Technical College of Building Materials, Qinhuangdao, Hebei Province \\ 066004 \\ hunter2011@foxmail.com
}

Keywords: Public Service, Sports Service for Community, Market

\begin{abstract}
Today the community sport has become a hot of popular sport, but how the community sports service keeps up with the pace of the socialist market economy is a problem in front of us. This paper from the perspective of the public service, analysis the community sports and noted the issues that hinder the development of community sports service and provides a guideline for sustainable development of the community sports service.
\end{abstract}

\section{The Interpretation of the Community Sports}

Community Sports mainly refers to the city community-based, community residents as the main object to community-based natural environment and sports facilities for the material basis to meet the sports needs of the community members, enhancing the feeling of community as the main purpose, to carry out regional local conditions sports activities.

With the development of community sports services and the gradual rise of community sports development, it is advantageous to guarantee the smooth development of community sports. Community sports organization services, facility services, fitness guide service and fitness information services constitute the main content of community service. Community Sports Service has an important role in the promotion of community spiritual civilization, sport life, sport socialization and so on. While accompanied by growth in demand for a wide range of residents, urban community sports service has become a very important part of community service, as currently it has no uniform definition of the concept, so in accordance with past practice and theoretical research found that can be community sports services broadly defined as such: grassroots urban communities and social service agencies as the main members of the community self-help and mutual aid towns, based on the full use of community resources inside and outside the sport, specifically to create conditions for sports activities of urban residents, provide collectively help of various events.

\section{The Community Sports Service in the Perspective of Public Service}

Community sports services within the scope of public services, we often say urban community sports service mainly refers to a public service within the community has to offer. The public service sport here has the non-competitive and non-exclusive nature of public goods Sports Services, is designed to meet the common needs of society. Community sports services essentially is a public welfare and non-profit, but with the further development of society, part of sports services can be implemented paid services.

With the progress and development of society, people understand modern society and public services have been further understanding. The so-called public service refers to the use of public power and public resources to provide the services citizens. The traditional theory believe: public service, "public" decision to provide public services is a government cannot shirk responsibility. However, those who think that modern economic theory: on the one hand, the diversity of public services, multi-level features, a single supply of government cannot meet the public demand for personalized, so that other social hosts involved in the provision of public services is necessary; another respect, many public services are not pure public service, it is only between quasi-public 
services between public service and private service, so other social hosts involved in the provision of these quasi-public services is also very possible.

\section{The Obstacles of the Development of Community Sports Service}

In the process of development of community sports services, the perennial habit and tradition hindered the further development of community sports services.

Firstly the recognize problem yet to be solved. Community sports service in the end is kind of social welfare, or the issue pertaining to the operation of the tertiary industry has been plagued by a community sports services further development. Understanding the differences in this respect for the different effects of the policies and regulations of community sports services such community sports development there is no clear direction.

Secondly, the traditional government structures and functions will be exercised by masked people's eyes, making them difficult to find the problem, therefore, limiting the accelerated development of community sports services.

Again, whether Government officials or ordinary people, for the public service provided by the government have become accustomed to, but there is a dependency, unwillingness to break this pattern. The previous rules and regulations formulated after several years has not been updated in time, even several years of reform and opening up, the country's economy has been greatly improved, people's living standards has been a qualitative leap today, as government community sports administration nor from work, methods, and even the new development ideas up to consider how to improve the efficiency, how to more effectively meet the needs of different community sports groups.

\section{The Sustainable Development Way of Community Sports in the Perspective of Modern Public Service}

The goals of sustainable development of community sports service are serving the community and continue to meet the growing demand sports of people. With the development of socialist modernization, urbanization, road gradually moving towards the right track, the community as an important part of the town, more and more attention. Community sports life become inseparable part of living. Therefore, the quality of service and sustainable community sport level become harmonious development of society, people's living standards to measure an important indicator. At this stage, our government has increased investment for the community to build sports facilities, this is obvious. However, due to the unbalanced development of our community, population many residents are quite different level and other objective reasons, resulting in community sports national direct investment in public goods demand does not fully meet the needs of community members.

As people's living standards improve, improve the material and cultural living standards resulting in further improvement of the spiritual and cultural trends, people will gradually diversified personalized direction for sports development needs, people have higher requirements for sports services. From sports, sports site selection, to improve the service system, the service director of specialization.

Improve community sports service levels is key. From a public service perspective, the emphasis on public services based on cooperation, emphasizing the government's service, emphasizing the rights of citizens. Therefore, from the perspective of government should strengthen investment advisory services and public resources; and from a personal point of view, an important body of health value, is the main indicator to measure the quality of people is the foundation and a quality of the population. Investing in health is equivalent to investment in the future economic development, we have a healthy society is to have a "wealth" or similar language has been hanging people's lips.

The nature of human development is human development, and human development depends on the underlying public service provision status of a country or region. Thus, the basic public service is an important condition for human development, but also an important part of human development. Now contradictory public services focused on the growing lack of public services residents demand 
and the overall supply of public services, the contradiction between the low quality, thus strengthening the government's public service functions, accelerate the improvement of public service status of community sports, will help ease China's current a variety of community sports services faced major problems as the smooth progress of the construction of a harmonious community, to stabilize the sustainable development of community sports services. Community public sports service supply process goods, in essence itself is a kind of socio-economic activities in such activities in how to give full play to the role of sport service organization, as much as possible in all aspects of sports services mobilize capital and resources, better serve the community, to serve the residents to become community sports to improve the level of key public services.

The normalization and legalization are the powerful guarantee for stable, fast and sustainable development of community sports service. CPC Central Committee, the State Council issued the "Circular on Further Strengthening and Improving Sports Work in New comments" a paper clearly states: "To gradually improve mass sports conditions, and strive to build a pluralistic mass sports service system, focus attention on venues and facilities, staff, information services three links, prominent schools, towns, communities, company four key. "File is easy to see from the above, the community is one of the four priorities, indicating the degree of national importance for community sports services. But our current sporting regulations is not perfect, the lack of the necessary legal guarantees effective community sport system, it is difficult for the community sports service to provide a solid and effective protection forward in the right direction. Community sport is an important part of fitness, although the country launched the "National Fitness Guidance Outline" in 1995, but has yet to complete a detailed introduction of the laws and regulations of community sports. However, community sports service healthy, stable and rapid and sustainable development, the need for good with suitable social environment, and this depends on the adaptation and communities to establish and improve a variety of sports-related laws and regulations. Particularly in relation to community sports venues and facilities, funding, organization and management, service staff distribution structure and other issues are harder to be recognized in law. It is worth mentioning that, due to the rapid development of the sports industry, resulting in management development organizations lag phenomenon occurs with suited, community sports service person to replace the legal system are quite serious, there is bull management there, so fitness their rights are not well protected, so that people lose their sense of security, greatly affected the enthusiasm of people to participate in sports. Therefore, accelerating the development of community sports services related laws and regulations, so that community sports work system to follow, according to the law, to ensure that community sports service activities legalized, institutionalized and regular, so as to promote the sustainable and rapid development of community sports services. In short, to create a favorable legal environment to properly resolve the process of marketization of public services in a variety of problems in the community sports services standardized.

Strengthening the construction of laws and regulations of community sports to accelerate the process of according to the management of community sports work. Establish and improve community sports management system, to explore the community sports management and operation mechanism of a line with Chinese characteristics. Standardize and improve community sports service system, the formation of multi-faceted, multi-purpose community sports services network structure. The three pillars of the laws and regulations of community sports, venues and facilities, constitute the social sports instructors, community sports only into the legal track, be possible to embark on the path of healthy development.

One effective way to solve the problem of the status quo at this stage of community sports facilities is to establish a better fitness facility service system, strengthen the functions of the community sports service, to explore the establishment of a public service facility sharing mechanism of the road. The rapid development of sports fitness and entertainment, making the rapid development of a wide range of community health club workout crowd to absorb possible; sport as a link established community, street, neighborhood, family community service network and gradually formed; use the weekend, the middle schools, institutions, enterprises and institutions of all the sports facilities open to the community and become community citizen fitness center; greening and beautifying the new site and 
take advantage of the beautiful natural environment opens up new communities of natural lawn, use built hillside forest campaign trail for fitness Residents provide ecological sports; other activities in the mining folk fitness methods, depending on the characteristics of the community, select the desired space, equipment small projects, the traditional sport and fashion combine to form a strong regional characteristics, colorful various types of eco-sports activities. All of these practices will be a better solution street sports and community sports practice problems, so as to lay a solid foundation for the establishment of a more complete specification of community sports fitness facilities service system.

Market is an inevitable result of the sustainable development of community sports services. With the deepening of the socialist market economy development and reform, understanding of public services also have a new understanding, from this perspective, the need to redefine the functions of the government and the market. For public services, especially those belonging to the community sports services quasi-public service, to be determined in the government provision of public services under the responsibility of the premise of the market incentives and competition management tools and measures to introduce, in some areas dilute the government's dependence, reduce the fiscal burden of government, while encouraging multi-level aspects of community sports services for investment. Market-based scheme is conducive to the combination of market mechanisms and public functions. Because diversity and multi-level public service has features, resulting in a single supply of government cannot meet the individual development needs in public groups, from this perspective, other social actors to actively participate in the provision of public services is quite necessary to a.

Community Sports Service is to serve all residents, but residents of the economic differences of income requires the development of community sports service to diversity. Because China is in a transition stage of social transformation, government investment in public sports undertakings cannot meet the needs of the masses, in order to meet the community's growing demand for sports, community sports service must take the market-oriented path of development. Through market making the community sports activities with the market potential of, by way of profitable operations, thereby widening development channels.

Broaden government financing channels, increase financing, adequate social idle funds to attract sports community public service in the past, a strong proponent of stock and stock cooperative system to attract a wide range of social investment, mobilizing all sectors of society Chung community resources in the short term sports, thus speeding up the development of community sports services. Public service market requirements is to the government on appropriate financing deregulation, changing the way traditional direct government financing, create more financing channels. But this process, coordinate the relationship between the different stakeholders is very important. While increasing introduction of market competition mechanism in the field of public service delivery, and strive to achieve the best supply of public services and effective optimal allocation of public resources. Government incentives and support to use the relevant policies and regulations to implement the functions of the Public Service of social transfer, the implementation of the principle of social responsibility altogether negative, driven by multiple investors into the community sports field of public social services, which make up the government for providing the right amount of service shortage of funds situation exists.

\section{Acknowledgements}

This paper belongs to the Qinhuangdao social science key applications project An Exploration on Sustainable Development of Sports Service for Community from the Perspective of Public Service in Qinhuangdao in 2012(201206198)

\section{References}

[1] B.Y. Fan, Community Sports Theory, M. Beijing: Beijing Sports University Press, 2003: 80

[2] X.M. Bao, The recognition of the relations between community sports service with several 
concept, J. Shandong Physical Education Institute, 2003,19 (2) 24-27

[3] Y.Z. Li, Analysis of some problems of public service marketization, J. Social Sciences, 2007, 8: 61-66

[4] S.Y. Gao, M.Y. Tan, J. Tian, The analysis about related issues of development of urban community sports service, J. Shanxi Sports Science, 2005, 11: 32-34

[5] M. Song, Z.P. Zhang. Market choice and practice of western public service reform, J. Economic Issues, 2007, 9: 122-125 